Journal of

Back and

Musculoskeletal

EST

Journal of Back and Musculoskeletal Rehabilitation 5 (1995) 105-106

Rehabilitation

\title{
Editorial
}

\section{Bifocals are a pain in the neck}

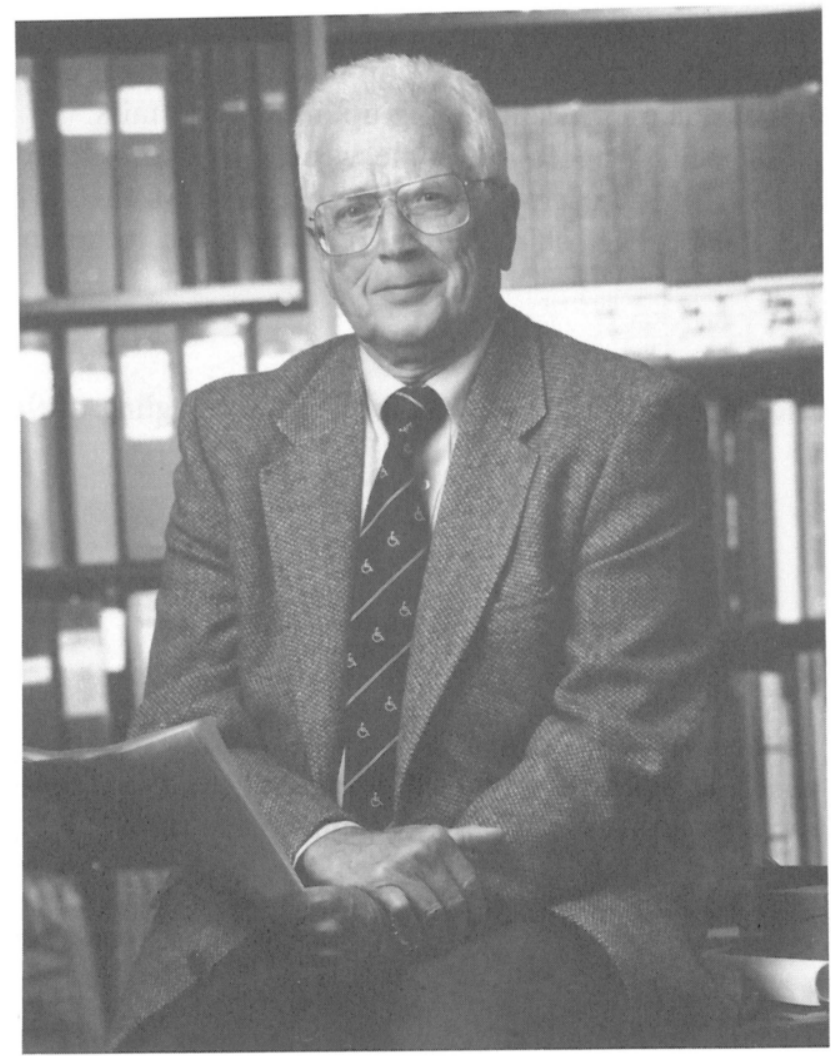

Ernest W. Johnson

Department of Physical Medicine and Rehabilitation, The Ohio State University, 370 West 9th Avenue, Columbus, OH 43210-1238, USA

1053-8127/95/\$09.50 ๔ 1995 Elsevier Science Ireland Ltd. All rights reserved. SSDI 1053-8127(94)00115-5 
I am truly confounded by the lack of understanding of the relationship of bifocal glasses to upper limb and neck pain.

In the 1930s it was called 'meter reader's disease'. Now it is overlooked but still a frequent cause of pain.

\section{Here's why.}

When one begins to have difficulty reading at arm's length, we know the lens is getting sclerotic and the onset of middle age is threatening.

Our cervical spine, especially at C5,6 (the most mobile of mid-cervical spine) is developing spurs. This, of course, is Mother Nature's attempt to stabilize a segment of the cervical spine where the disk is losing water, narrowing, and thus stability.

Our need to have a pair of reading glasses or to add a reading segment to our corrective lenses is urgent. (Since we cannot elongate our arms.)

The friendly oculist accepts our prescription for bifocals and makes the helpful suggestion to place the reading segment low to minimize the 'image jump' - an upsetting factor for the bifocal neophyte. Image jump is always a treacherous obstacle especially going up and down stairs.

This 'helpful' gesture by the oculist necessitates the wearer to hyperextend, even more, the neck to read at eye level. This maneuver of the cervical spine further narrows the vertebral foramen - already compromised by spurs at the joints of Luschka (medial margin of the foramen).

What happens?

Patient complains of posterior shoulder and upper limb pain with tingling of the thumb and index finger.

Diagnosis?

C-6 radiculopathy.

Treatment?

Home cervical traction - intermittent, of course. N.B. no distraction occurs in cervical spine until $45 \mathrm{lbs}$ is reached. And move the reading segment so that the upper edge is $1 \mathrm{~mm}$ below the margin of lower lid. If a job requires eye level activity, put the reading segment on top of the lens.

No-line glasses are particularly malignant in this situation since they result in this painful posture even more!

For those individuals who think immediate relief is necessary and yell for the scalpel (most likely an anterior body fusion); this is not an easy solution but our experience over 35 years has been that this abrupt loss of motions by blocking two vertebrae will eventuate in the same problem at the disk above within a year or two.

Our advice is conservative management and let Mother Nature immobilize the segment over the next 5 years.

And - never attend air shows or sit in the front pew at church. 